\title{
ARTIGO
}

\section{Pesquisa docente no espaço constitutivo da formação dos profissionais da Ciência da Informação no Brasil}

\author{
Teachers' research and its effects in the education \\ of Information Science professionals in Brazil
}

Francisco das Chagas de SOUZA ${ }^{1}$

RE S U M O

Este trabalho analisa o tema da pesquisa docente, o modo como ele pode ser percebido em nosso ambiente educacional próximo constituído pelo campo mais amplo das Ciências da Informação realizada no Brasil. Considera as conseqüências dessa percepção e alerta para a necessidade de criar-se um quadro mais favorável à pesquisa; especialmente, à pesquisa voltada para a ação pedagógica, o que viria a fortalecer consideravelmente o ensino de graduação nos cursos da área existentes -e ofertados neste ano de 2002- em 40 Instituições de Ensino Superior brasileiras.

Palavras-chave: Ensino de Ciências da Informação, pesquisa docente, pesquisa pedagógica.

\section{A B S T R A C T}

This paper analyses the theme of teachers' research and the ways it may be perceived in our own educational environment, constituted by the wide-ranging field of the Information Science carried on throughout Brazil. Considering the consequences of misperceptions, it alerts to the need for creating a more favorable

\footnotetext{
1 Bibliotecário, Doutor em Educação, Professor Adjunto IV, Departamento de Ciência da Informação, Universidade Federal de Santa Catarina, Campus Universitário, Trindade, 88040-900, Florianópolis, SC, Brasil.

Caixa Postal 5121 - Ag. Trindade. E-mail: chagas@ced.ufsc.br / souza@amja.org.br

Recebido e aceito para publicação em 8/7/2003.
} 
environment towards teachers' research; mainly, towards research intended for pedagogical action. Such research will strengthen considerably the undergraduate education imparted in IS courses, existing and being offered in 2002 at 40 Brazilian institutions of High-Education.

Key words: Information Science college program, teachers' research, pedagogical research.

\section{N T R O D U Ç Ã O}

No mundo atual, mais fortemente penetrado pela cultura pragmática dos Estados Unidos, vulgarmente denominada de cultura ocidental, vivemos claramente uma era de discursos, como fórmula determinante de uma economia da existência. Discursos que movem o mundo financista da economia com a força normatizadora, belicista e de crença cega nos mais eticamente distorcidos conteúdos veiculados por todas as mídias e que são tomados como realidades e verdades.

Discursos, isto é, o pensamento traduzido para o verbo, foi sempre, e biblicamente, a origem e a estrutura do mundo. Por milênios forjam as tradições, religiões, estados, profissões, representando a relação conceber / fazer num dizer acumulado, num reter memorizado, seletivamente filtrado pela experiência e práxis humana. Parte substancial do concebido e do dito / retido deslocou-se da materialidade natural para constituir uma segunda natureza, a das máquinas, que nos últimos séculos vem sendo aperfeiçoada pela aceleração forjada pela racionalidade científica (DUPAS, 2001) originada por uma criação filosófica européia, cartesiana e mecanicista, linear e quantitativa, mas também, mais recentemente, a partir do início do século $X X$, com maior intensidade, pela descoberta de como manipular produtivamente o mundo subatômico dos quanta e do caos. Sem entrar em uma apreciação valorativa, temos a consciência de que estamos agora neste mundo assim como ele é e até aqui assim construído. Não necessariamente parece ter sido planejado para assim ser mas certamente foi sendo assim configurado pelos desejos que vêm prevalecendo na grande teia do discurso, dito universal, por parte dos que se comprazem pela busca de um mundo melhor, mais limpo, mais cheiroso, com a produção de respostas mais rápidas, criando e usando recursos e técnicas que permitam mais saúde e longevidade para os humanos, dentre outros desejos.

$\mathrm{Na}$ origem da aceleração industrialista que vem construindo o mundo presente e durante a trajetória dessa construção não foram poucos aqueles que se assombraram com a incerteza do porvir. De outro lado, pensadores e filósofos viram no discurso, ou seja na ação comunicativa, o motor dessa construção (também demolição) permanente. Marx, por exemplo, interpretado há alguns anos por Berman (1986), apontava para a vulnerabilidade da tradição ao afirmar que toda a solidez desmancha-se no ar. Lefebvre (1991) via na escrita (a representação material do discurso) o fundamento da civilização e da opressão. Débord (1997), encontrava no discurso representado pelas imagens o fundamento da sociedade moderna como espetáculo que seria em essência a presentificação da realidade, ou seja, "o desenrolar é tudo". Baudrillard (1995) percebia que o discurso que era representado pelo consumo não conhecia e nem ignorava completamente o mundo, simplesmente promovia o seu "desconhecimento". Key (1996) observava que pelo e para o discurso se constituiu uma indústria poderosa voltada para a venda de qualquer coisa que tem como base a concepção de que todas as coisas são relativas, tornando mais fácil o processo manipulatório das mentes. 
Em complemento, Dreifuss (1996) identificava que vivíamos pela metade dos anos noventa do século XX uma época de perplexidades, onde se percebia, segundo sua análise, que classes sociais e estados eram "fenômenos históricos, sujeitos à vida e à morte de suas existências e representações (...) tencionados pela infocracia mediática e te(le)matizada, pelo marketing dos indutores de interesse e opinião...". No final dos anos noventa, Castells (1999, p. 505) na trilogia "A era da informação" via uma sociedade em rede, aliás título do volume primeiro da coleção, no qual afirma: "Estamos entrando em um novo estágio em que a Cultura refere-se à Cultura, tendo suplantado a Natureza a ponto de a Natureza ser renovada ("pareservada") artificialmente como uma forma cultural... a informação representa o principal ingrediente de nossa organização social, e os fluxos de mensagem e imagens entre as redes constituem o encadeamento básico de nossa estrutura social". Também pelo final dos anos noventa do século XX, Morin (1999), ao pensar sobre as disciplinas (uma categorização discursiva do saber constitutivo de ramos profissionais) enxergava que não seria a sua destruição, mas a sua articulação (articulação desses discursos constitutivos de ramos profissionais) que poderá responder mais efetivamente às necessidades do avanço e aperfeiçoamento humano.

Esse conjunto de percepções, que sintetiza uma vasta produção acerca dos rumos sociais e humanos dos anos recentes e nos anos vindouros, traz à discussão o sentido dado pela teoria sociológica do conhecimento formulada por Berger \& Luckmann (1985) de que a realidade é uma construção social e pela formulação de Habermas (1999) de que a existência humano-social é resultante da ação comunicativa, isto é, das conversações, diálogos e interação humanas. De outro lado, o grande sentido de tudo isso, presente todo o tempo, é o da mudança como a constante da existência.
Em nossa realidade mais próxima e em nossa vida recente, por um breve momento histórico, se tentou compreender o contrário, ou seja, que a institucionalização da realidade (o discurso da ordem) seria permanente e a ação comunicativa mero instrumental para essa ordem. Assim, há ainda um forte saudosismo que vê a escola-especialmente o ensino superior de campos profissionais - como uma representação insubstituível do discurso da ordem. Com isso, muito da perplexidade presente advém da idéia da educação universitária em certos campos como permanente e das respectivas profissões como sólidas em seus fundamentos e metodologias para todo o sempre. E não são mais isso, aliás, nunca o foram de fato. Sua reconfiguração, ou seja, seu redesenho como um discurso diferente do até então vigente, é questão que queira-se ou não está sempre posta na ordem do dia, e mais fortemente já há algum tempo e nesse bojo aparece com um certo ar de novidade um novo espaço de ação docente que é a pesquisa. A dificuldade mais visível é, em vários campos acadêmico-profissionais, como construir um discurso novo que defina, com a consciência da provisoriedade concreta, o ser e o fazer designável como pesquisa durante a formação inicial de profissionais.

Ao tempo em que se coloca a pesquisa como a forma de se fazer uma educação mais eficaz com as vantagens que o método clínico, como apresentado por Perrenoud (2002), pode oferecer, as tecnologias atuais de comunicação e informação recriam o ambiente de ensino superior como T. Dwyer mostra em artigo, no qual relata os impactos dessas tecnologias no campo das Ciências Sociais. Dwyer (2001) em 1999, viu numa universidade inglesa em que visitou a alteração da relação tradicional professor e aluno. De uma situação onde o professor tradicional era o fornecedor de informações para os alunos havia se chegado a uma em que o professor "orienta o aluno e o ajuda a entender tudo o que descobre nas suas pesquisas". 
Na seqüência deste texto, se pretende refletir sobre o tema pesquisa docente e de como ele pode ser percebido em nosso ambiente educacional próximo, constituído pelo campo mais amplo da Ciência da Informação realizada no Brasil.

\section{A PESQ U ISA D O CENTE}

\section{0 que é a pesquisa docente}

Na medida em que possamos considerar que se realiza uma prática de pesquisa que o professor desenvolve contratualmente como docente, poderemos estar afirmando que pesquisas da mesma natureza feitas por outros profissionais que não atuam na docência são diferentes. A realidade universitária atual não confirma totalmente isto. Em quase todos os campos, a pesquisa feita por docentes avança vertical e horizontalmente, seja para atender a necessidades de avanço do conhecimento básico, seja para responder a necessidades específicas de empresas ou angústias sociais de caráter mais humanístico e apenas em parte para atender à sua própria ação pedagógica. Mesmo as grandes companhias industriais, de serviços ou os governos têm se aproximado das Universidades para dessas extrair conhecimento ou soluções a partir do envolvimento de docentes e de seus orientandos em resposta a questões específicas. De outro lado, a resposta não é apenas esta. Muito mais que em qualquer ambiente de apropriação, sistematização, produção e transmissão de conhecimento, a docência universitária carece demais de produzir conhecimento e soluções para melhorar a compreensão que o estudante universitário tem do seu ambiente social e para encontrar a medida próxima ao ideal de que um envolvimento por via de estágios, por exemplo, não se dê em prejuízo de um adequado desenvolvimento cognitivo e domínio dos conteúdos e metodologias que possibilitem ao hoje estudante exercer com criatividade e adequação ética a sua profissão futura.

Derek Bok, no livro "Ensino Superior" escrito em 1986, ao estudar a evolução da Universidade estadunidense, com o olhar de quem detinha o posto de Presidente da Universidade Harvard, faz algumas considerações sobre as mudanças que poderiam ocorrer no sistema universitário daquele país. Nas possibilidades que ele aponta, se percebe que 0 docente, como ele vê, carece de mais estímulo ao trabalho educacional. Finalizando, diz que:
órgãos do governo e fundações poderiam fazer muito mais para financiar os esforços de aprimo- rar o processo de educação (...) As agências de financiamento também poderiam apoiar a pesquisa sobre eficiência do ensino e do aprendizado. Com o tempo, tal assistência daria aos professores a retroalimentação que os estimularia a continuar tentando novos métodos de instrução, ao mesmo tempo em que ofereceria aos corpos docen- tes a oportunidade de aperfeiçoar a qualidade da educação através de um processo bem informado de tentativa e erro (BOK, 1988, p.229).

Isto pode evidenciar que, independentemente de qual seja o país observado, os processos relativos à ação educacional constituem o segmento mais pobre da atuação docente e o menos amparado com investimento para pesquisa.

No Brasil, o ambiente de ensino superior, especialmente aquele inserido nos sistemas público federal e estadual, onde está instalada a maioria dos Programas de Ensino da Ciência da Informação, evidencia hoje boa parte dos fatores discutidos por Bok e merece a mesma observação que ele fazia para o contexto estadunidense de 16 anos passados, isto é, necessidade de meios para a pesquisa sobre o 
ensino superior possibilitando que, ao menos, o processo experimental que se adota, de tentativa e erro, seja bem informado.

Desse ponto de vista, poderíamos constituir ou avolumar um segundo ramo da pesquisa docente que se faz a partir da ação pesquisadora docente no espaço da ação pedagógica e que é diferente da maior parte da pesquisa que se realiza na universidade brasileira hoje, a qual está voltada para o aperfeiçoamento técnico-científico do conhecimento a ser aplicado pelos profissionais que está sendo graduado nas licenciaturas e bacharelados. A urgência disso é que o desconhecimento sobre os processos de formação, por não estar sendo pesquisado devidamente, pode ser um dos elementos que gera uma taxa média de evasão no ensino superior muito maior que um terço das vagas conquistadas nos processos seletivos para ingresso.

Uma olhada sobre a pesquisa financiada hoje realizada no Brasil, a maior parte pelos docentes na universidade brasileira, considerando a atuação da pós-graduação, ou mesmo dos Grupos de Pesquisa cadastrados pelo Conselho Nacional de Desenvolvimento Científico e

Tabela 1. Investimentos realizados pelo CNPq em Fomento à Pesquisa em 1998-2000.

\begin{tabular}{|c|c|c|}
\hline Grandes Áreas & Fomento à Pesquisa & Participação (\%) \\
\hline & (Em Mil Reais) & \\
\hline & 1998 & 1998 \\
\hline & 1999 & 1999 \\
\hline & 2000 & 2000 \\
\hline \multirow[t]{3}{*}{ Ciências Exatas, da Terra e Engenharia } & 12.119 & 38,7 \\
\hline & 18.670 & 37,4 \\
\hline & 40.138 & 41,5 \\
\hline \multirow[t]{3}{*}{ - Engenharia e Ciências da Computação } & 8.499 & 27,1 \\
\hline & 10.468 & 20,9 \\
\hline & 20.852 & 21,6 \\
\hline \multirow[t]{3}{*}{ Ciências da Vida } & 12.649 & 40,4 \\
\hline & 23.576 & 47,2 \\
\hline & 44.408 & 46,0 \\
\hline \multirow[t]{3}{*}{ Humanidades } & 6.508 & 20,8 \\
\hline & 7.736 & 15,3 \\
\hline & 11.964 & 12,3 \\
\hline \multirow[t]{3}{*}{ - Ciências Sociais Aplicadas } & 2.521 & 8,0 \\
\hline & 2.441 & 4,8 \\
\hline & 4.435 & 4,5 \\
\hline \multirow[t]{3}{*}{ - Ciências Humanas } & 3.410 & 10,9 \\
\hline & 4.418 & 8,8 \\
\hline & 6.556 & 6,7 \\
\hline \multirow[t]{3}{*}{ - Lingüística, Letras e Artes } & 575 & 1,8 \\
\hline & 777 & 1,5 \\
\hline & 973 & 1,0 \\
\hline
\end{tabular}

Fonte: http://www.cnpq.br/servicos/estatisticas/globais.htm 
Tecnológico (CNPq), daria um perfil quantitativo não muito distante do que se encontra representado nas estatísticas do Fomento ofertado pelo órgão nos três últimos anos da década de noventa (Tabela 1). Segundo as estatísticas que se pode acessar em sua homepage, a Grande Área de Humanidades onde mais se insere a pesquisa social, histórica e pedagógica, contou com um montante de recursos sempre inferior a uma das subáreas de Exatas, da Terra e Engenharias, no caso Engenharias e Ciência da Computação. Esse desequilíbrio se agrava na medida em que progressivamente aumenta, ano a ano, no triênio considerado, o percentual dos recursos de fomento para a pesquisa básica e tecnológica. Com isso, o que as universidades brasileiras, principais clientes dos recursos do CNPq, mais realizam é a pesquisa voltada para aplicações em campos profissionais e científicos, o que deixa toda a pesquisa humano-social, aí incluída a pesquisa docente de caráter pedagógico, praticamente à deriva. Um dado a ser destacado é que, em relação a 1998, a área de Humanidades perdeu em 2000 quase $40 \%$ de recursos, em valores relativos, o que agrava mais ainda a possibilidade de financiamento a pesquisas de docentes voltadas a explicar e compreender as ações tipicamente pedagógicas da docência.

É evidente que isto faz repercutir no Brasil o que existe em boa parte do mundo, ou seja, uma tendência que enviesa a ação da universidade para o campo operacional (CHAUÍ, 2002). Contudo, nesta instituição estão presentes, como número permanente, uma parcela que varia de $2 \%$ a $10 \%$ da população de cada país. Um número tão expressivo de indivíduos, que sairá de seus campi para realizar serviços para a sociedade e para a própria universidade terá que ser construído em sua personalidade social, ética e profissional. Para isso, precisará conviver com e assimilar valores que dêem contextualização moral e ética aos conhecimentos científicos e técnicos que também absorverá. Por esta razão, além da eficiência com que forem transmitidos tais conhecimentos, há a necessidade de cuidado pedagógico com os modos de convivência nas práticas de aprendizagem, com os meios oferecidos, com os ambientes e laboratórios utilizados, com os discursos conexos empregados, com as atitudes e posturas docentes, com as histórias profissionais bem-sucedidas, com a eficácia da deontologia de cada profissão, com o exercício da crítica social, dentre outros fatores que se traduzem na formação de modelos ou paradigmas de convivência, solidariedade e responsabilidade profissional e social.

\section{0 que busca a pesquisa docente}

A pesquisa realizada pelo docente, em âmbito geral, considerada, com parte integrante de seu trabalho pode objetivar vários aspectos. Alguns desses aspectos estarão mais fortemente ligados à produção de respostas para o ambiente profissional no qual visa inserir novos profissionais, como interpretar ou ampliar conteúdos teóricos e aplicados aperfeiçoar serviços ou produtos.

Outros aspectos poderiam estar mais fortemente dirigidos ao ambiente de ensino como: melhoraria no desempenho pedagógico; trabalhar melhor os conteúdos; trabalhar melhor as relações pessoais e humanas que envolvem os estudantes; dominar as ferramentas metodológicas da educação; e selecionar e adaptar as ferramentas metodológicas da educação à área profissional da qual se incumbe.

Contudo, pelos dados sobre o fomento oficial à pesquisa no Brasil, supõe-se ser cada vez menor a quantidade de recursos para este segundo conjunto de aspectos.

Se olharmos para a população universitária do país, considerando que a maior parte ingressa e está matriculada em Cursos das áreas de Ciências Sociais e Humanas (66,5\%) (Tabela 2) e dentro destas um grande percentual 
está em cursos de Licenciatura e Pedagogia, pode-se perguntar como ou com que qualidade esta educação está sendo realizada. Se nas ciências exatas, tecnológicas e da vida para onde vai mais de $80 \%$ dos recursos de fomento à pesquisa se faz pouca ou nenhuma pesquisa docente em Educação, como com os míseros recursos que as ciências humanas e sociais recebem há possibilidade de realização da pesquisa docente sobre a ação pedagógica?

A comparação entre as Tabelas 1 e 2 , por seus dados, não deixa muita dúvida sobre a concentração e expansão dos recursos para as áreas em que a pesquisa é predominantemente de caráter técnico e tecnológico e a asfixia de recursos para todo o restante.

\section{Por que a pesquisa docente busca 0 que busca}

Como qualquer outra atribuição que lhe é conferida, a pesquisa é realizada pelo docente por várias motivações. Contudo, a política de ciência e tecnologia seguida pelo país é a grande determinante e tende a fomentar mais a pesquisa orientada à produção de respostas para o ambiente profissional onde ingressará os recém-formados que para as pesquisas voltadas a fornecer respostas suficientes e adequadas para fortalecer o ambiente de ensino.

Em razão disso o docente se planeja para, como investigador:

conhecer as demandas e necessidades ditas de mercado; conhecer as limitações políticas e econômicas ao atendimento dessas demandas; conceber formas de ação e os conteúdos necessários para responder à demanda e romper, inclusive, limites éticos; traçar um mapa da atuação profissional hoje; traçar um mapa da atuação profissional possível ou futura; traçar um mapa com as articulações ou interpretação e explicação da convivência e sobrevivência de sua área profissional em competição com as outras profissões e com as expectativas ditas mercadológicas; fortalecer profissional e cientificamente sua área profissional.

Se em última instância a pesquisa docente está fadada a fortalecer a profissão final para qual o curso foi constituído, naquilo que ela tem de ciência e prática, não dá para desprezar

Tabela 2. Matrículas em Cursos presenciais em 30/4/2000 - Brasil.

\begin{tabular}{lccc}
\hline Áreas Gerais & Total Absoluto & Participação (\%) & Agrupamento \\
\hline Educação & 584.664 & 21,7 & 3,2 \\
Humanidades e Artes & 88.559 & 41,6 & 66,5 \\
Ciências Sociais, Negócios e Direito & 1.122 .142 & & \\
\hline Subtotal 1 & & 8,6 & \\
\hline Ciências, Matemática e Computação & 233.726 & 2,3 & 1,7 \\
Engenharia, Produção e Construção & 234.497 & 1,6 & 33,1 \\
Agricultura e Veterinária & 63.260 & 323.196 & 100,0 \\
Saúde e Bem-Estar Social & 44.201 & 100,0 & \\
Serviços & & & \\
\hline Subtotal 2 & 2.694 .245 & & \\
\hline Total & & & \\
\hline
\end{tabular}

Fonte: http://www.inep.gov.br/download/censo/2000/Superior/Sinopse Superior-2000.pdf 
um componente importante de qualquer pesquisa feita por docente, para qualquer finalidade, deveria ter que é o conhecimento ético e a difusão de uma deontologia profissional que perpassa todos as razões listadas acima. Pelo conhecimento do fundamento ético é que o grupo profissional pode definir conscientemente deveres profissionais. Neste aspecto, um dos fundamentos da pesquisa sobre a ação pedagógica está ligado à relação direta, presencial ou à distância de um educador ou tutor com seu aluno e nisto se trava imediatamente uma aplicação moral que pode configurar um princípio ético saudável ou destruidor e esse é um matiz significativo da relação entre ensino e aprendizagem.

\section{Condições para a realização da pesquisa docente}

A pesquisa docente, mesmo que condicionada pelas forças que estão acima do professor individualmente situado, requer algumas pré-condições, seja tanto a que promove a ampliação do conhecimento de sua profissão quanto a que estuda a sua prática pedagógica. Como a vertente mais visível favorece a primeira, para ela são canalizados muito mais elementos de apoio ou de favorecimento à qualificação.

Deste modo, ela afirmará menos ou mais itens tais como os abaixo que constituem condição basilar para o seu desenvolvimento:

Convicção da importância da pesquisa; capacitação acadêmica para a sua realização; escolha de temas promissores; visão da dinâmica que orienta o movimento: realidade / sociedade / comunicação; obtenção de infra-estrutura de pesquisa (laboratórios equipados); captação de recursos para fomento (custeio de material, comunicação, etc.); disposição de tempo remunerado para a pesquisa; disposição de tempo remunerado e de bolsas para treinamento de iniciantes científicos.
Se, ao contrário, a pesquisa é realizada como um procedimento de análise das práticas (PERRENOUD, 2002), ou espécie de auto-avaliação do docente, de sua atuação, algumas dessas pré-condições não são reconhecidas como necessárias. Embora não seja verdade, pois esta modalidade de pesquisa também consome tempo para preparação e acompanhamento, ela corre o risco de não ser valorizada e ao mesmo tempo corre o risco de não ser computada como atividade real e nem receber o amparo para sua plena realização. É aqui onde aparece um pouco mais claramente a percepção de porque mesmo quando possa estar acontecendo não tem condições de se visibilizar: falta ao docente, além de tudo o mais, o tempo para escrevê-la e escrever sobre ela e faltam os canais adequados para a sua difusão, por parecer algo menor e, muitas vezes, até não científico e não necessário para a formação de profissionais.

\section{A PESQ UISA D O CENTE NA ÁREA DAS CIENCIAS DA I N F ORM A ÇÃ O NO BRASIL}

Pode-se apresentar duas considerações iniciais sobre a pesquisa docente na área das Ciências da Informação no Brasil. A primeira é a de que não há dados muito evidentes quando estamos observando a pesquisa voltada à compreensão e explicação da ação pedagógica. Alternativamente, talvez se possa apurar algo pelo caminho de verificação do que está sendo veiculado nos periódicos da área ou de campos correlacionados, como o da educação. A segunda é considerarmos que a produção dos programas de pós-graduação da área envolve os docentes orientadores e aí as temáticas das pesquisas orientadas poderiam indicar os núcleos de interesse que vêm sendo explorados. Nesta segunda vertente, trabalho recente apresentado no IV Encontro Nacional de Pesquisa e Pós-Graduação em Ciência da 
Informação, Brasília, 2000, Pinheiro (1999/2000), ("Infra-estrutura da pesquisa em Ciência da Informação no Brasil”), que pode ser lido em conjunto com o artigo de Oliveira (2001), dá um perfil global que inclui uma rápida análise sobre os programas e cursos de pós-graduação; recursos humanos; fomento à pesquisa; disseminação da informação; e bibliotecas, centros de informação e laboratórios existentes até aquele momento no país.

Subordinando o olhar à primeira consideração apontada acima, e em uma rápida análise, verifica-se a existência de pouquíssimos textos nos últimos anos que relatam o desenvolvimento de experiências voltadas ao teste, aperfeiçoamento e compreensão de procedimentos pedagógicos na área, ou mesmo de textos que examinem criticamente a ação docente realizada, como uma pesquisa empírica e situada. Raros textos, dentre os que temos examinado no Núcleo de Informação, Pesquisas e Estudos em Educação Bibliotecária (NIPEEB) do Departamento de Ciência da Informação da Universidade Federal de Santa Catarina (UFSC), têm aparecido nos periódicos Encontros Bibli e Informação \& Sociedade: estudos. Em outros periódicos, como Ciência da Informação, Revista de Biblioteconomia de Brasília, por exemplo, têm aparecido também de forma rara, textos sobre mudanças curriculares em cursos da área, o que sugere um envolvimento, embora não tão evidente, com a temática.

No que toca ao exame a partir da segunda consideração, com base nas informações disponíveis, em 23/7/2002, no site da Associação Nacional de Pesquisa e Pós-Graduação em Ciência da Informação e Biblioteconomia (ANCIB), apenas um Programa, o da Universidade de Brasília (UNB), dispõe de linha de investigação que tem relação próxima com esta preocupação, isto é, a linha "Formação Profissional e Mercado de Trabalho" e uma única docente atuando na mesma. De outro lado, o trabalho de Susana Mueller, Antonio Miranda e Emir Suaiden "A pesquisa em Ciência da Informação no Brasil análise dos trabalhos apresentados no Encontro Nacional Associação Nacional de Pesquisa e Pós-Graduação em Ciência da Informação e Biblioteconomia (IV ENANCIB), Brasília, 2000", quando compara a evolução dos Grupos Temáticos do I ao IV ENANCIB, 1994 a 2000, encontra no Grupo "Formação Profissional / Mercado de Trabalho" uma produção constante. Contudo, o quadro apresentado merece melhor exame, penetrando--se no conteúdo tratado nos textos, para melhor aquilatar sua relação com a discussão peda-gógica, pois no caso do IV ENANCIB, de 19 trabalhos apresentados no Grupo apenas 4 puderam ser classificados no subgrupo Formação Profissional e Educação Continuada e desses 1 tratava da necessidade de se oferecer Educação Continuada para auxiliares de Bibliotecas Universitárias (BAPTISTA, 1999/2000). De outro lado, em programas como o a UFPB, algumas dissertações tratando da temática foram defendidas, por exemplo, em 1998, Lima (1998) e Diniz (1998), analisando, respectivamente o ensino de Biblioteconomia na Universidade Federal do Amazonas e na Universidade Federal da Paraíba.

O texto já referido de Lena Vânia (Pinheiro,1999/2000), apresentava no final de 2000 dados significativos quanto ao número de Teses e Dissertações defendidas no país, considerando 30 anos do Programa de Mestrado da Universidade Federal do Rio de Janeiro (UFRJ), Instituto Brasileiro de Informação e Tecnologia (IBICT), 28 do Mestrado da Universidade de São Paulo (USP), 24 do Mestrado da Universidade Federal de Minas Gerais (UFMG), 23 dos Mestrados da Universidade Federal da Paraíba (UFPB) e da PUCCAMP, 22 do Mestrado da UNB e 2 dos Mestrados da Universidade Estadual de São Paulo (UNESP) e da Universidade Federal da Bahia (UFBA) e 8 anos dos Doutorados da UNB e Universidade de São Paulo (USP), 6 do Doutorado do IBICT e 3 do Doutorado da UFMG. Tinha-se um total de 848 Dissertações de 
Mestrado e 65 Teses de Doutorado. Associe-se a esses dados, 179 sócios ativos na ANCIB, 62 grupos de pesquisa registrados na área, uma média de 9 projetos anuais aprovados pelo $\mathrm{CNPq}$ entre 1995 e 1999 e um único evento de pesquisa em Ciência da Informação no País o ENANCIB. De outro lado, quando aquela autora analisou os conteúdos dos artigos publicados de 1997 a 1999 no periódico Ciência da Informação, considerando a participação percentual de $3 \%$ ou acima não encontrou dentre os 14 assuntos mais abordados, o tratamento do tema pesquisa educacional em Ciência da Informação no país. Num outro ângulo, é assunto que requer melhor exame, incluindo análise de conteúdo mais verticalizada, na medida em que o artigo de Oliveira (2001) que parte da análise de 94 relatórios de pesquisa em Ciência da Informação financiados entre 1984 e 1993 pelo CNPq encontra que em $19 \%$ deles o tema versava sobre Formação em Biblioteconomia e Ciência da Informação. Contudo, na apreciação da autora "Muitos desses estudos resultaram em propostas de melhoria dos perfis profissionais. Outros se dedicaram a reflexões das atividades de ensino e pesquisa na pós-graduação impactados, principalmente, pelas novas tecnologias" (p. 151).

Considerando que no âmbito da graduação, a área das Ciências da Informação está hoje composta por 27 instituições que oferecem o Curso de Biblioteconomia; 6 que oferecem cursos de Biblioteconomia e Arquivologia; 2 que oferecem Curso de Ciência da Informação e 1 de Arquivologia, 1 de Museologia; 1 de Administração da informação e 1 de Gestão da informação, totalizando $40 \mathrm{IES}$, comprometidas com a capacitação de pessoal na área, parece discutível que dos 8 Mestrados e 4 doutorados ora instalados e em funcionamento, apenas 1 Mestrado disponha explicitamente de 1 linha correlacionada ao assunto e apenas 1 orientador seja identificado. Além disso, não parece ser quantitativamente significativa a representação do tema nos periódicos e livros publicados no país. Talvez, por isso, que a Associação Brasileira Educação em Ciência da Informação (ABECIN), sucessora da Associação Brasileira de Ensino de Biblioteconomia e Documentação (ABEBD), esteja se propondo a estabelecer uma linha editorial que inclui o seriado Teoria \& Crítica e a coletânea Documentos ABECIN como recurso para suprir esta e outras carências relacionadas à ação pedagógica nos cursos da área das Ciências da Informação que operam no Brasil. Além disso, as listas de discussão da ABECIN se apresentam como um outro canal que horizontalizando e dando caráter mais informal à comunicação do docente de Biblioteconomia possa fazer fluir experiências e compreensões de práticas que melhor e mais rapidamente difundam o que ocorre individual e coletivamente nas equipes dos Cursos da área que funcionam no país.

\section{FORTA LE CIM E N TO D O CAMPO PROFISSIONALE CIENTÍFICO NO PAÍS}

Na medida em que a docência no campo mais amplo da Ciência da Informação vem se profissionalizando no país, especialmente a partir dos anos da década de 1980, com a contratação de professores em tempo integral de 40 horas semanais e, em larga medida nas IES federais, em Dedicação Exclusiva, vê-se progressivamente se instituir a ação em pesquisa, tomada como responsabilidade e atividade esperada. Olhando de outro ângulo, para além dos termos constantes nos contratos de trabalho, observa-se que houve a percepção da necessidade correlata de capacitação acadêmica adequada para prover os Departamentos dos respectivos Cursos de quadros docentes com cada vez mais titulação e, se possível, com doutores. Portanto, é muito recente a criação dos meios mínimos para o estabelecimento de um programa de pesquisa sustentável. Mas é ainda uma pesquisa 
para um dos rumos, isto é, para promover a ampliação do conhecimento das e para as profissões das Ciências da Informação e mesmo nesta dimensão as conclusões dos estudos tanto de Suzana Mueller e outros quanto de Oliveira (2001) permitem perceber que se está numa espécie de estágio inicial. Concluindo a partir dos dados com que trabalharam e interpretaram, Suzana Mueller e outros afirmam nas "considerações finais", por exemplo, que "é uma área em estágio de formação de seus pesquisadores"; que "as instituições mais ativas em pesquisas são as universidades onde há cursos de pós-graduação" e que há "ainda uma certa deficiência no uso de métodos e técnicas de pesquisa" Mueller et al. (1999/2000, p. 306).

Este cenário constituiu-se na vertente de pesquisa mais amparada, com algum subsídio de fomento ou com alguma articulação a partir dos Programas de Pós-Graduação. Embora os relatos afirmem um progressivo aumento de qualidade de produção desse rumo de pesquisa nas duas últimas décadas, ele parece ainda estar em seus primórdios.

Um ponto que pode ser tomado como relevante na discussão, é o que se faz dos textos apresentados como dissertações e teses em Ciências da Informação no Brasil, que pelos dados de Pinheiro (1999/2000), somavam 913 volumes até o ano 2000 ? Se, supostamente, eles analisam e interpretam a realidade presente no cenário profissional e científico da área no país, tentando responder a demandas colocadas pela sociedade, por que não estão majoritariamente integrados como bibliografia nos programas de ensino dos cursos de graduação existentes? Por que a grande maioria desta vasta coleção de saber produzida no país não se transforma em livros impressos ou em outros formatos e suportes? Por que, enfim, ainda temos um ensino de graduação que se afasta ou é afastado do conhecimento que os pesquisadores da área, nos espaços de pesquisa da área, mesmo que em estágio inicial, estão produzindo?
Se a pesquisa em Ciências da Informação realizada no país ainda é tão frágil que não consegue gerar sistematizações sobre o saber nacional produzido, se a capacidade de iluminação que o "topo" poder gerar sobre a "base" ainda está quase apagada, se esse conhecimento ainda não se permite ser explorado para efeitos de transposição didática e colocado à disposição da graduação, é porque uma lacuna severa está aí para ser superada. E aí está um espaço para a pesquisa didática e pedagógica ser executada.

Sem que um programa nacional, com provável indução pela $A B E C I N$, envolvendo também os Programas de Pós-Graduação e a ANCIB na função de articuladores de linhas de investigação apropriadas, não for rapidamente fomentado, continuará a ocorrer uma resposta vazia ou inadequada da pesquisa em Ciências da Informação no Brasil para o fortalecimento da ação profissional e científica no país. Na medida em que a realidade, para bem funcionar, supõe a imbricação dos fazeres acadêmicos e profissionais, dos métodos, dos instrumentos, ou como diria Morin (1999), da articulação dos saberes, não dá para deixar a pesquisa sobre a ação pedagógica, se e quando existe, ser apenas a ação diletante de um ou outro docente.

Se como diz Bourdieu (1996), o conhecimento cultural e escolar representa um capital e no nosso contexto este capital está sendo elaborado em certas instâncias e não adequadamente distribuído porque a habilidade da transposição e o espaço da transposição e passagem desse capital não faz as pesquisas que definem os contornos e os modos de ação nesse mesmo espaço, pode estar acontecendo uma das seguintes situações: a) o capital de conhecimento constitutivo do campo das Ciências da Informação que se transmite em nossos cursos não incorpora majoritariamente o nosso próprio esforço e aí precisamos saber porque não o faz? b) não temos ainda a 
competência para fazer do saber que produzimos o saber conseqüente, ou seja, conteúdos ensináveis? ou c) não temos o fácil acesso a este vasto acervo construído com investimento brasileiro em bolsas de pesquisa, financiamento de projetos, etc. e isto nos coloca como alienistas e alienados no contexto desta sociedade que, de tão boa, mas também de tão desinformada, não pode perceber que, de certo modo, estamos cometendo um atentado à sua cidadania o que mereceria ser examinado a partir de pesquisa sob o enfoque da ética social e/ou histórica.

\section{CON SIDERAÇÕ ES FINA IS}

Nesta análise, partimos da idéia de que há uma percepção de estamos situados num mundo que, por ser construído discursivamente, vem se expandindo de tal maneira que provoca muito mais rapidamente o rompimento avassalador das pretensas certezas. Há implicações disso, também na atuação docente, na medida em que a ruptura das certezas insere a pesquisa como atividade inescapável do fazer do professor. De outro lado, verifica-se que do docente se exige um envolvimento maior com a pesquisa que promove a ampliação do conhecimento profissional do campo de atuação para o qual o Curso em atua foi criado a qual recebe algum incentivo. Em face disso, a pesquisa sobre a ação pedagógica fica reduzida, majoritariamente, à condição de prática diletante dos docentes interessados em melhorar sua relação de trabalho didático-pedagógico, produzindo mais qualidade no seu desempenho e podendo inserir com propriedade metodológica o saber novo nos conteúdos com que trabalha.

No que toca à situação brasileira e, especialmente, na área de Ciências Humanas e Sociais, a pesquisa que promove a ampliação do conhecimento profissional dos vários campos está em estágio de sufocamento financeiro, pois as verbas para o fomento estão sendo reduzidas progressivamente. Quanto às Ciências da Informação, a pesquisa está num estágio inicial, gerando conhecimento a base de metodologias limitadas e, mais grave, não atinge, como esperado, o espaço acadêmico do ensino de graduação. Diante disso, se torna urgente que ações sejam realizadas por entidades como a ABECIN que, integradas a entidades como a ANCIB, possam dimensionar formas de fazer um aproveitamento melhor do conhecimento produzido pela pesquisa que promove a ampliação do conhecimento profissional do campo de atuação para o qual os Cursos de graduação da área foram criados. Isto poderia se dar pela implementação de uma jornada de atividades voltadas ao incentivo dos docentes a fim de que possam criar e/ou integrar projetos de pesquisa sobre a ação pedagógica nos cursos de graduação pertinentes às Ciências da Informação instalados nas 40 IES que os oferecem assim como envolver os Programas de Pós-Graduação que efetivamente desejem e tenham suporte teórico e humano para se interessarem pelo assunto.

\section{RE FE R Ê N CIAS}

BAPTISTA, S. Formação profissional e mercado de trabalho. Revista de Biblioteconomia de Brasília, Brasília, v.23/24, n.3, p.435-438, especial 1999/2000.
BAUDRILLARD, J. A sociedade de consumo. Rio de Janeiro: Elfos, 1995. p.25.

BERGER P.; LUCKMANN, T. A construção social da realidade. 6.ed. Petrópolis: Vozes, 1985. 
BERMAN, M. Tudo que é sólido desmancha no ar: a aventura da modernidade. São Paulo: Companhia das Letras, 1986.

BOK, D. Ensino superior. Rio de Janeiro: Forense-Universitária, 1988.

BOURDIEU, P. O novo capital. In: BOURDIEU, P. Razões práticas sobre a teoria da ação. Campinas: Papirus, 1996. p.35-52.

CASTELLS, M. A sociedade em rede. 2.ed. São Paulo: Paz e Terra, 1999. p.505.

CHAUÍ, M. A universidade operacional. ADUNICAMP Publicações. Disponível em: <http://www. adunicamp. org.br/publicacoes/revista1/chaui.htm>. Acesso em: 24 jul. 2002.

DÉBORD, G. A sociedade do espetáculo. Rio de Janeiro: Contraponto, 1997. p.17.

DINIZ, E. S. Currículo e sociedade: uma análise do ensino de graduação em biblioteconomia na UFPB. João Pessoa, 1998. Dissertação (Ciência da Informação). Universidade Federal da Paraíba, 1998.

DREIFUSS, R. A época das perplexidades: mundialização, globalização, planetarização: novos desafios. Petrópolis: Vozes, 1996. p.328-329.

DUPAS, G. Ética e poder na sociedade da informação: de como a autonomia das novas tecnologias obriga a rever o mito do progresso. 2.ed.rev.ampl. São Paulo: UNESP, 2001.

DWYER, T. Inteligência artificial, tecnologias informacionais e seus possíveis impactos sobre as ciências sociais. Sociologias UFRGS, Porto Alegre, v.3, n.5, p.58-79, 2001.
HABERMAS, J. Teoria de la acción comunicativa. Madrid: Tauros, 1999. $2 \mathrm{v}$.

KEY, W.B. A era da manipulação. 2.ed. São Paulo: Scritta, 1996. p.30.

LEFEBVRE, H. A vida cotidiana no mundo moderno. São Paulo: Ática, 1991. p.164-165.

LIMA, R.M. Ensino de biblioteconomia e realidade social no estado do Amazonas: o aparente e o concreto de uma relação. 1998. Dissertação (Ciência da Informação) - Universidade Federal da Paraíba, João Pessoa, 1998.

MORIN, E. Articular os saberes. In: ALVES, N.; GARCIA, R.L. (Org.). O sentido da escola. Rio de Janeiro: SEPE, 1999. p.65-80.

MUELLER, S. P. M.; MIRANDA, A; SUAIDEN, E. J. A pesquisa em Ciência da Informação no Brasil: análise dos trabalhos apresentados no IV ENANCIB, Brasilia, 2000. Revista de Biblioteconomia de Brasília, Brasília, v.23/24, n.3, p.293-308, 1999/2000. Edição Especial.

OLIVEIRA, M. A pesquisa científica na ciência da informação: análise da pesquisa financiada pelo CNPq. Perspectivas em Ciência da Informação, Belo Horizonte, v.6, n.2, p.143-156, 2001.

PERRENOUD, P. A prática reflexiva no ofício do professor: profissionalização e razão pedagógica. Porto Alegre: Artmed, 2002.

PINHEIRO, L.V.R. Infra-estrutura da pesquisa em Ciência da Informação no Brasil. Revista de Biblioteconomia de Brasília, Brasília, v.23/24, n.3, p.367-390, 1999/2000. Edição Especial. 
